\title{
Effect of Chest Physiotherapy and Recruitment Maneuvers on Hemodynamics and ICU Stay of Mechanically Ventilated Patients with Acute Lung Injury.
}

\author{
Naglaa Gamal El-dien Abd-Elhafez, Warda Youssef Mohamed, Mona Aly Mohamed, Mervat Anwar Abdel- \\ Aziz \& Kahled Mohamed Morsy .
}

Assistant Lecturer in Critical Care \& Emergency Nursing, Sohag University Egypt.

Professor of Critical Care \& Emergency Nursing, Cairo University Egypt.

Lecturer in Critical Care Nursing, Assiut University Egypt.

Lecturer in Critical Care Nursing, Assiut University Egypt .

Lecturer in Anesthia \&ICU, Faculty of medicine, Assiut University Egypt.

\begin{abstract}
Background Acute lung injury Patients may require mechanical ventilation to survive Chest physiotherapy \& Recruitment maneuvers are two methods that improve respiratory efficiency and promote Hemodynamic stability Aim To investigate effect of chest Physiotherapy \& recruitment maneuvers on hemodynamic parameters and length of ICU stay of mechanically ventilated Patients with Acute lung Injury Design Quasi-experimental design

Setting The study was carried out in trauma intensive care unit at Assiut university hospital. Subjects: A convenience sample of 60 matched patients and randomly assigned into two equal groups diagnosed as having an acute lung injury, coma scale $\geq 13$, on mechanical ventilation Tools Tool: acute lung injury mechanically ventilated patient assessment sheet were utilized to collect data Methods study group was exposed to two sessions/day of chest physiotherapy\& recruitment maneuvers until disconnection from mechanical ventilator in addition to the routine hospital care. Results Significant statistical was put into evidence between the two studied groups in the hemodynamic parameters HR was $(96.71 \pm 11.39)$ in study group $(110.64 \pm 11.14)$ control group after $30 \mathrm{~min}$ $(\mathrm{p}=0.001)$ after $12(93.16 \pm 22.79)$ in study group $(91.07 \pm 7.0)$ in control group $(\mathrm{p}=0.05)$ Temperature in control group (38.9 to 38.6) (37.3 to 37.7) in study group ( $\mathrm{p}=0.001)$ control group stayed longer in ICU than study group $(\mathrm{p}=0.001)$ Conclusion Combining Chest physiotherapy Recruitment maneuvers are of great values for improvement of respiratory efficiency and promote Hemodynamic parameters Replication of the study on larger propriety sample is recommended.
\end{abstract}

Key words: Chest physiotherapy, Recruitment maneuver, Hemodynamics, ICU stay, Mechanical ventilator \& Acute lung Injury.

\section{Introduction}

Acute Lung Injury (ALI) is defined as: Bilateral pulmonary infiltrates on a chest radiograph consistent with the presence of pulmonary edema, no evidence of left atrial hypertension and if measured a pulmonary capillary wedge pressure of $\leq 18 \mathrm{mmHg}$ .Oxygen criteria to include the ratio of arterial oxygen to the fraction of inspired oxygen $\left(\mathrm{PaO}_{2} / \mathrm{FiO}_{2}\right)$ to be $\leq 300 \mathrm{mmHg}$. ALI is caused by any stimulus of local or systemic inflammation, principally sepsis ,pneumonia ,major trauma ,pulmonary aspiration and near drowning ,burns ,inhalation of noxious fumes ,fate embolism ,massive blood transfusion ,Amniotic fluid embolism ,air embolism, eclampsia ,poisoning, radiation . Patients with acute lung injury may require mechanical ventilation to survive, minimize damage to injured lungs; small Ventilatory volumes and low plateau pressures have been used these reduce mortality and the duration of mechanical ventilation (Boriosi et al., 2011, Phua, 2009, Spieth et al., 2009 ).
Recruitment maneuvers (RMs) is an important component of a lung protective ventilation strategy are often used to treat patients with acute lung injury to increase intrathoracic pressure, re-inflate collapsed regions of the lungs by briefly raising transpulmonary pressure to levels higher than achieved during tidal ventilation to promote alveolar recruitment, leading to increased end-expiratory lung volume which improve gas exchange (Bernard et al., 2011).

Chest physiotherapy is the term for a group of treatments designed to improve respiratory efficiency, promote expansion of the lungs, strengthen respiratory muscles, eliminate secretions from the respiratory system, mobilize or loose secretions in the lungs and respiratory tract help patients to breathe more freely and to get more oxygen into the body. Chest physiotherapy is a method of clearing the airway from excess mucus. It is based on the theory that when various areas of the chest and back are percussed, shock waves are transmitted through the chest wall, loosening the 
airway secretions. If the patient is positioned appropriately, the loosened secretions will then drain into the upper airways, where they can then be cleared using coughing and deep breathing techniques. Chest physiotherapy is given to recruit collapsed distal lung units to optimize ventilation and perfusion (Potter \& Perry, 2011, Morton, 2009) .

Hemodynamic monitoring is central necessarily forms for a major aspect of nursing care to ICU patients and it is Avery important aspect especially for mechanically ventilate patient the critical care nurse undertakes comprehensive cardiovascular assessment of the patient to determine adequacy of cardiac output, observe for complications associated with poor cardiac output. This involves assessment of heart rate and rhythm, blood pressure and central venous pressure peripheral perfusion, urine output and chest X-ray, as well as serum electrolytes. (Philip Woodrow, 2012 ).

Nursing management for patient with (ALI) on mechanical ventilator include the following Performing frequent assessments including level of consciousness and vital signs, verifying prescribed ventilator settings and appropriate alarm limits, close monitoring of airway pressure including (mean airway pressure, peak inspiratory pressure ,plateau pressure ), secure the endotracheal tube and respond to and ventilator alarms, adhere to infection control guidelines and identify complications or mechanical problems associated with MV, such as an air leak or kink in the ventilator circuit Assessing the adequacy of cardiac output. Evaluating the adequacy of oxygenation. (Smeltzer \& Bare ,2012 ).

\section{Significance of the study}

Statistics of Egyptian trauma Intensive Care Unit at Assuit University Hospital in the years of $\mathbf{2 0 1 0}$ \& 2011) revealed that the number of patients admitted to trauma intensive care unit were 775 (approximately $75 \%$ of them were connected to mechanical ventilation). (Hospital records of Assuit University,2010-2011).Clinical observation of researcher revealed that most of those patients were suffering from many of respiratory and other systemic problems which might endanger their life, increase hospital stay and the period of mechanical ventilation and reduce rate of turnover and burden hospital resources, despite these complications can be minimized or prevented.

\section{Aim of the study}

This study was carried out to investigate the effect of chest Physiotherapy and recruitment maneuvers on Hemodynamic parameters and ICU stay of mechanically ventilated Patients with Acute lung Injury.

\section{Patients and method}

\section{Research design}

Quasi-experimental research design were utilized in this study

Hypotheses: To fulfill the aim of the study the following research hypothesis were formulated:-

Hypothesis (1) The post mean homodynamic parameters of study group subjects will be better than those of the control group subjects.

Hypothesis (2) The length of ICU stay of study group subjects will be shorter than that of the control group subjects.

\section{Setting}

The study was conducted in trauma intensive care units of Assiut university hospitals.

\section{Patients}

A convenience sample of 60 male \& female adult patients who were admitted to trauma intensive care unit connected to mechanical ventilator, diagnosed as acute lung injury, hemodynamically stable with mean arterial pressure of more than $60 \mathrm{~mm}$, hemoglobin of not less than $8 \mathrm{gm} / \mathrm{dl}$,Lung injury score of $0.1-2.5$. They were matched \& randomly assigned into two equal groups 30 patient each according to computer based program .

Patients with severe head injury, increase intracranial pressure and those who are potentially liable to develop pathologically raised intracranial pressure, having acute pulmonary edema, terminal diseases, inoperable cancers, age of more than 60 years, cardiac abnormality or disease ,Pregnancy, autoimmune diseases. were not included in the study The potentially selected patients were matches according to the following Matching criteria:- age range from $1-3$ years, sex, lung injury scale scores of $0.1-2.5$, Glasgow coma scale score of $\geq 13$ ,Diagnosis ,comorbidity diseases (e.g. diabetes mellitus ) in to 2 equal groups of 30 patients each ,then they were randomly assigned in to study \&control group.

\section{Study tool}

Tool were utilized to collect data is:-Acute lung injury mechanically ventilated patient assessment sheet

Assessment sheet were developed by the researcher after extensive literature of review from.(Alspach,2006,smeltzer\& Bare, 2010 and Morton G.P., et al., 2009). It composed of 7 main areas .The validity \& reliability of these tools were revised by a panel of medical and nursing experts then pilot study was done.

Part 1:-Socio- demographic data (age ,sex,). 
Part (2) : Clinical data (past medical diseases, medical diagnosis,).

Part (3): Assessment of homodynamic parameters (Temperature $(\mathrm{T})$, heart rate (HR), blood pressure (BP) \& mean arterial pressure (MAP) and CVP readings).

Part (4) : Assessment of number of days on mechanical ventilator, length of stay in ICU.

Part (5) : Assessment of chest X-ray to detect site and type of lesion by radiologists .

Part 6:- assessment of baseline galscow coma scale

Part (7) : Assessment of lung injury score on admission and discharge

lung injury score developed by (Maskara 2000) Is designed to assess patient for the presence and extent of a pulmonary damage . It can be used both at the onset of a lung disorder and during the course of the illness to monitor changing lung involvement. parameters used are (1) chest X-ray evaluated for alveolar consolidation (2) ratio of the partial pressure of oxygen in arterial blood to the inspiratory fraction of oxygen(3) PEEP level if ventilated (4) respiratory compliance. The score was calculated based on the results of logistic regression analysis. score $=$ suma valores parameters maximum summation of parameters $=16$, minimum summation of parameters $=0$, score 0 : no lung injury, score $0.1-2.5$ : mild-tomoderate lung injury, score > 2.5: severe lung injury (ARDS)

\begin{tabular}{|l|l|c|}
\hline Parameter & \multicolumn{1}{|c|}{ Finding } & Value \\
\hline \multirow{4}{*}{ Rx. Torax } & no alveolar consolidation & 0 \\
\cline { 2 - 3 } & 1 quadrant & 1 \\
\cline { 2 - 3 } & 2 quadrant & 2 \\
\cline { 2 - 3 } & 3 quadrant & 3 \\
\cline { 2 - 3 } Hypoxemia & 4 quadrant & 4 \\
\hline \multirow{5}{*}{ PaO2/FIO2 } & $>300$ & 0 \\
\cline { 2 - 3 } & $225-299$ & 1 \\
\cline { 2 - 3 } & $175-224$ & 2 \\
\cline { 2 - 3 } & $100-174$ & 3 \\
\cline { 2 - 3 } & $<100$ & 4 \\
\hline \multirow{5}{*}{ PEEP } & $<=5 \mathrm{~cm} \mathrm{H} 2 \mathrm{O}$ & 0 \\
\cline { 2 - 3 } & $6-8 \mathrm{~cm} \mathrm{H} 2 \mathrm{O}$ & 1 \\
\cline { 2 - 3 } & $9-11 \mathrm{~cm} \mathrm{H} 2 \mathrm{O}$ & 2 \\
\cline { 2 - 3 } & $12-14 \mathrm{~cm} \mathrm{H} 2 \mathrm{O}$ & 3 \\
\cline { 2 - 3 } & $>=15 \mathrm{~cm} \mathrm{H} 2 \mathrm{O}$ & 4 \\
\hline & $>=80 \mathrm{~mL} / \mathrm{cm} \mathrm{H} 2 \mathrm{O}$ & 0 \\
\cline { 2 - 3 } & $60-79 \mathrm{~mL} / \mathrm{cm} \mathrm{H} 2 \mathrm{O}$ & 1 \\
\cline { 2 - 3 } & $40-59 \mathrm{~mL} / \mathrm{cm} \mathrm{H} 2 \mathrm{O}$ & 2 \\
\cline { 2 - 3 } & $20-39 \mathrm{~mL} / \mathrm{cm} \mathrm{H} 2 \mathrm{O}$ & 3 \\
\cline { 2 - 3 } & $<=19 \mathrm{~mL} / \mathrm{cm} \mathrm{H} 2 \mathrm{O}$ & 4 \\
\hline
\end{tabular}

\section{Content validity}

The tools were tested for content related validity by jury of 7 specialists in the field of critical care nursing and critical care medicine from Assiut \& Cairo University, and the necessary modifications were done.

\section{A pilot study}

A pilot study was carried out on 6 patients to test the clarity and applicability of the tools and time needed to collect the data. The tools were applicable and there was not any modification.

According to the results of the pilot study subjects included in to the study.

The Reliability was done on tools by Cronback's Alpha it was (0.95)

\section{Protection of human rights}

An official Permission was taken by the researcher from the head of trauma intensive care unit at Assiut university hospitals after explanation the aim and nature of the study, confidentiality and anonymity of the subjects were ascertained, Subjects were assured that can they withdraw from the study at any time without any rational at any time, Informed consent was obtained from each patient or from the responsible person for the unconscious patients.

\section{Procedure}

\section{Preparatory phase}

Construction of data collection tools used in this study were developed by the researcher based on reviewing the relevant literature .

An official Permission was granted by the researcher from the head of trauma intensive care unit at Assiut university hospitals after explanation the aim and nature of the study.

An approval was obtained from the local ethical committee and the study was followed the common ethical principles in clinical research.

\section{Implementation and evaluation phases}

The implementation phase was conducted over a period of nineteen months starting from (May 2012 to December 2013) because of the rate of attrition. Glasgow coma scale and acute lung injury score were utilize to select patient of $\mathrm{GCS} \geq 13$, $\mathrm{PaO}_{2} / \mathrm{fio}_{2} \leq 300$ then during this phase 30 legible patients who are welling to participate in the study were selected to constitute the control group, then their matches (30 patients) who are welling to participate in the study also were recruited to constitute the study group subjects .Both of two groups were received the routine hospital management and been assessed utilizing the three study tools as a base line assessment, each of the study groups subjects were exposed to the following interventions 
Each patient of the study group subjects were exposed in addition to routine hospital care to two sessions/day of chest physiotherapy\& recruitment maneuvers done by the researcher until disconnection from mechanical ventilator $\&$ according to physician prescription and his condition on daily bases. However control group subjects were exposed to routine hospital care only, both groups were monitored 3 times/day. The control group subjects were evaluated in the same way as the study group subjects including evaluation of heart rate, temperature, respiration, MAP and CVP readings evaluated immediately before the application of the maneuvers ).Then the recruitment maneuvers were applied by the researcher twice daily at which the researcher increased positive airway pressure to 30 or $40 \mathrm{~cm} \mathrm{H}_{2} \mathrm{O}$ for 30 to 40 seconds at the end of the 30 second period ,PEEP was gradually reduced in 3to 5- $\mathrm{cm} \mathrm{H}_{2} \mathrm{O}$ increments back to the baseline PEEP over a period of 2 minutes. and the immediate post evaluation was conducted half an hour\& 12 hour utilizing to the same parameters ,then these process was repeated according to patient's condition and physician description .

- Calculations were made of the $\mathrm{PaO}_{2}: \mathrm{FiO}_{2}$ ratio, All indices were measured to obtain baseline values and also used to monitor lungs improvement by the end of the study for both groups.

- Monitoring of variables was performed at baseline data , 30 minutes \& 12 hours after CPT\&RM as study group in order to compared to control group .

Routine hospital care

- Positioning patient according to ICU schedule of turning right side, left side and back don't preferred if patient hemodynamically unstable

- Routine chest physiotherapy (suction , percussion,vibration) was done only by nurses when secretions massive interfere with oxygenation and according to patient condition

Description of the chest physiotherapy procedure Study group

- Each patient was placed in baseline supine position with head of bed elevated 30 degree for 10 minute before commencement of study.

- The measurements of hemodynamic parameters were done before starting and after $30 \mathrm{~min} \&$ after 12 hours of chest physiotherapy and recruitment maneuver

- Patient was turned to the postural drainage position for 15 minute according to affected segment on chest $\mathrm{x}$-ray which reported by physician.

- Each postural drainage position was maintained for 5 minute and with 10 minutes of mechanical percussion and vibration followed by suction.
- Postural drainage positions were modified according to the patient's condition and tolerance warrant to prevent irritation caused by clapping the bare chest with mechanical precursor. A gown was used over the chest and avoiding places of electrode places .

- Percussion and vibration were applied over the lung .commonly accepted anatomical landmarks for percussion and vibration includes $10^{\text {th }}$ thoracic vertebra posteriorly and the xiphiod a anteriorly with normal respiration

- Percussion and vibration was avoided over the kidney, spinal column, breasts, floating rib, scapula and sternum.

- Suction was done with a sterile technique .patient were pre-oxygenated with $100 \%$ before suction and manually ventilated with a self inflated bag in between suction catheter passes the amount of secretions were collected and a sputum trap amount was recorded.

- A suction procured was accomplished before getting in postural drainage and following percussion and vibration the suction time less than 10 seconds to prevent desaturation.

- During turning the patient any tubes and connections attached to the patient was observed as ECG monitor,endotracheal tube ,feeding tube ,patient cuitical to ventilator, chest tube , urinary catheter ,arterial line ,peripheral line and central venous pressure line to avoid pulling, stretching or kilning these tube were avoided .

- By the end of the session leaving the patient to the routine nursing interventions.

- Chest physiotherapy procured was given 1 hour before feeding.

- The aerosolized treatment or bronchodilator prescribed by physical were given 15-30 minutes before chest physiotherapy .

\section{Control group}

The control group subjects were receiving the routine hospital care and evaluated in the same way as the study group subjects. the researcher observed the control group and the routine care the nurse give it to them.

\section{Statistical analysis}

All data were recorded in a special chart for every patient. The collected data were coded, analyzed and tabulated .Data entry and analysis were done using SPSS 17.0 statistical software package. Data were presented using descriptive statistics in the form of frequencies and percentages for qualitative variables, and means and standard deviations for quantitative variables. Quantitative continuous data were compared using analysis of variance test in case of comparisons between two independent groups. Using 
chi-square test for non-parametric data to determine significant statistical significant differences were considered when P-value used as follows
$\mathrm{P}>0.05$ non significant significant

\section{Results}

A convenient sample of 60 critically ill adult patients admitted to trauma intensive care unit at Assiut University hospital they were reviewed for potential enrollment in the study. Were randomly assigned into two equal groups was carried out to investigate the effect of chest Physiotherapy and recruitment maneuvers on Hemodynamics parameters(heart rate, blood pressure \&mean arterial pressure and CVP), and length of ICU stay of mechanically ventilated Patients with Acute lung Injury.

Table (1):- Percentage distribution of study and control group as regards socio-demographic characteristics \& clinical data $(n=60)$.

\begin{tabular}{|c|c|c|c|c|c|}
\hline \multirow{2}{*}{ Variables } & \multicolumn{2}{|c|}{ G1 "study group "n=30 } & \multicolumn{2}{|c|}{ G2 "control group " $n=30$} & \multirow{2}{*}{$P$ value } \\
\hline & $\mathbf{N}$ & $\%$ & $\mathbf{N}$ & $\%$ & \\
\hline Age" years" & & & & & \multirow{6}{*}{0.88} \\
\hline $20<30$ years & 7 & 23.3 & 7 & 23.3 & \\
\hline $31<40$ years & 14 & 46.6 & 14 & 46.6 & \\
\hline $41<50$ years & 5 & 16.6 & 5 & 16.6 & \\
\hline $51<60$ years & 4 & 13.3 & 4 & 13.3 & \\
\hline Mean \pm SD & \multicolumn{2}{|c|}{$40.60 \pm 11.2$} & \multicolumn{2}{|c|}{$40.16 \pm 11.4$} & \\
\hline Sex & & & & & \\
\hline Male & 21 & 70.0 & 21 & 70.0 & 0.37 \\
\hline Female & 9 & 30.0 & 9 & 30.0 & \\
\hline past medical history & & & & & \\
\hline Cardiac disorder & 0 & 0.0 & 1 & 3.3 & \\
\hline Renal disease & 5 & 16.6 & 5 & 16.6 & 0.15 \\
\hline Diabetes mellitus & 6 & 20 & 6 & 20 & \\
\hline Hepatic disorder & 1 & 3.3 & 0 & 0.0 & \\
\hline No past history & 18 & 60.0 & 18 & 60.0 & \\
\hline Diagnosis & & & & & \\
\hline Brain edema & 1 & 3.3 & 3 & 10.0 & \\
\hline Root traffic accident & 13 & 43.4 & 13 & 43.4 & 0.27 \\
\hline Multiple fracture & 11 & 36.6 & 9 & 30.0 & \\
\hline Stap wound & 5 & 16.6 & 4 & 13.3 & \\
\hline Near drawing & 0 & 0.0 & 1 & 3.3 & \\
\hline $\begin{array}{l}\text { Site of Lung lesion according to } \\
\text { chest } x \text {-ray on admission }\end{array}$ & & & & & \\
\hline Right & 8 & 26.7 & 7 & 23.0 & 0.17 \\
\hline Left & 3 & 10.0 & 3 & 10.0 & \\
\hline Bilateral & 19 & 63.3 & 20 & 66.7 & \\
\hline lung injury score on admission & & & & & \\
\hline Mild (0.1) & 20 & 66.7 & 22 & 73.3 & 0.08 \\
\hline Moderate $(\leq 2.5)$ & 10 & 33.3 & 8 & 20.0 & \\
\hline
\end{tabular}

Chi-square test \& Independent samples t-test $\quad P>0.05$ non significant $* P<0.05$ significant $\quad * * P<0.01$ moderate significant $\quad * * * P<0.001$ highly significant 
Hypothesis (1) the post mean homodynamic parameters of study group will be better than those of the control group. Covered in table (2

Table (2):- Vital signs and hemodynamic parameters mean values for chest physiotherapy \& recruitment maneuver all through the assessment in both groups $(n=60)$.

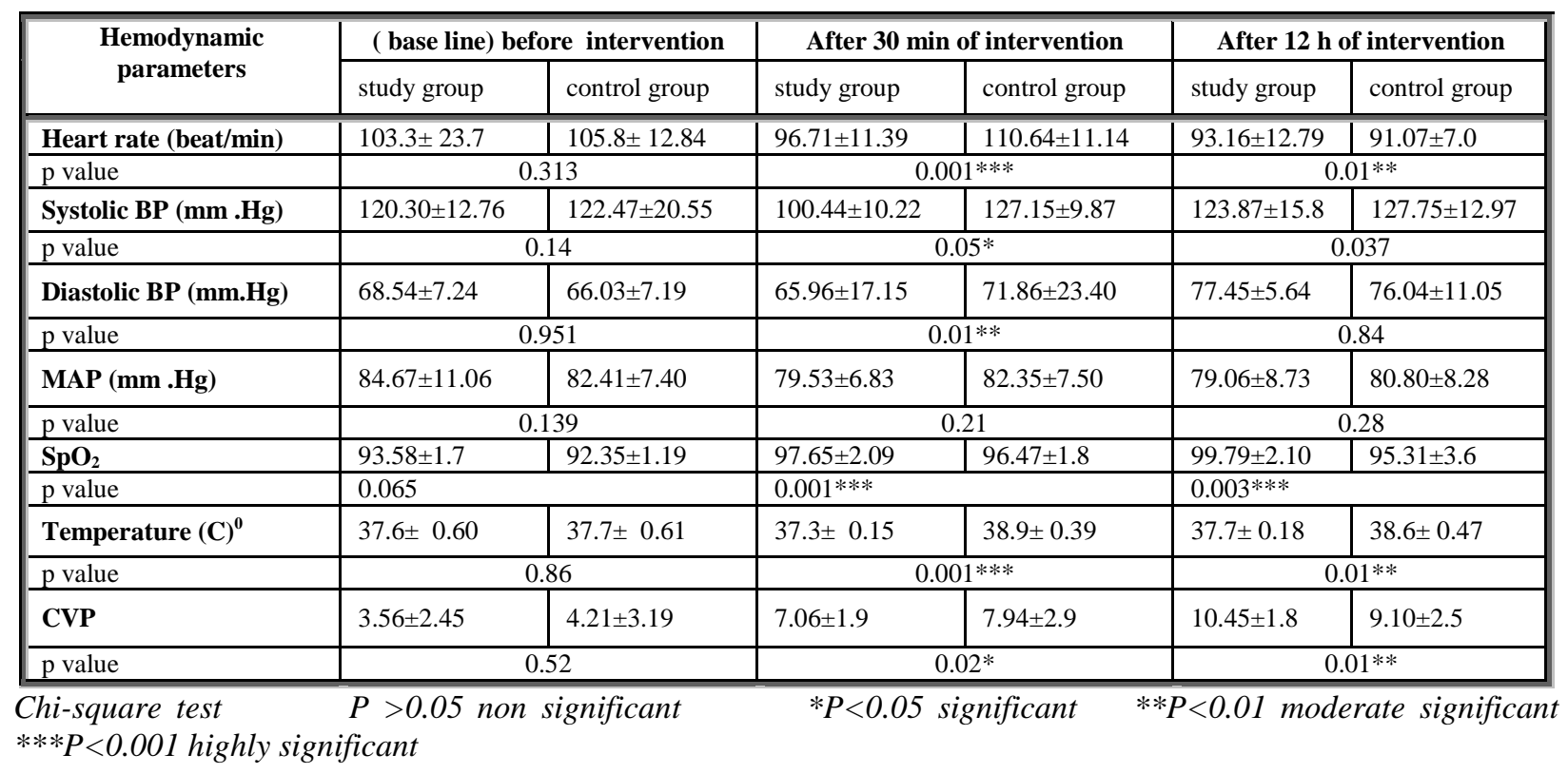

Hypothesis (2) the length of ICU stay of study group will be shorter than that of the control group. Covered in table (3).

Table (3):- Comparison between the two studied groups in relation to duration of ventilator dependency \&length of ICU stay in study and control group $(n=60)$.

\begin{tabular}{|c|c|c|c|}
\hline Variables & G1 "study group "n=30 & G2 "control group " n=30 & $P$ value \\
\hline Duration on MV (days ) & $14.0 \pm 5.9$ & $20.0 \pm 6.1$ & $0.001 * * *$ \\
\hline length of ICU stay (days ) & $15.8 \pm 5.5$ & $25.5 \pm 8.5$ & $0.001 * * *$ \\
\hline
\end{tabular}

Table (4):-Comparison between the two studied groups in relation to chest $x$-ray findings on discharge $(\mathbf{n}=60)$.

\begin{tabular}{|l|l|c|c|c|c|c|}
\hline \multicolumn{2}{|c|}{ Variables } & \multicolumn{2}{|c|}{ G1 "study group "n=30 } & G2 "control group " n=30 & \multirow{2}{*}{ P value } \\
\cline { 3 - 7 } & N & \% & N & \% & \\
\hline Sites of lung lesion & No affected & 22 & 73.3 & 10 & 33.3 & \\
according to chest x- & lesion & 4 & 13.3 & 8 & 26.7 & \multirow{2}{*}{$0.001 * * *$} \\
rayon discharge & Right lesion & 3 & 10.0 & 8 & 26.7 & \\
& left lesion & 1 & 3.3 & 4 & 1313.3 & \\
& Bilateral lesion & & & & & \\
\hline
\end{tabular}

Chi-square test $P>0.05$ non significant $\quad * P<0.05$ significant $\quad * * P<0.01$ moderate significant $\quad * * * P<0.001$ highly significant $\mathrm{PaO}_{2} / \mathrm{fio}_{2}$ the ratio of partial pressure of arterial oxygen to fraction of inspired oxygen. 
Table (5):- Comparison between the two studied groups in relation to occurrence of complications in study and control group by the end of the study $(n=60)$.

\begin{tabular}{|c|c|c|c|c|c|c|}
\hline \multirow{2}{*}{\multicolumn{2}{|c|}{ Complications }} & \multicolumn{2}{|c|}{ G1 "study group "n=30 } & \multicolumn{2}{|c|}{ G2 "control group " $n=30$} & \multirow[t]{2}{*}{$P$ value } \\
\hline & & $\mathbf{N}$ & $\%$ & $\mathbf{N}$ & $\%$ & \\
\hline Frequency of mortality & $\begin{array}{l}\text { Death } \\
\text { Live }\end{array}$ & $\begin{array}{c}4 \\
26\end{array}$ & $\begin{array}{c}13.3 \\
86.7 \%\end{array}$ & $\begin{array}{c}3 \\
27\end{array}$ & $\begin{array}{l}10.0 \\
90.0\end{array}$ & 0.73 \\
\hline Frequency of fever & $\begin{array}{l}\text { Yes } \\
\text { No }\end{array}$ & $\begin{array}{c}8 \\
22\end{array}$ & $\begin{array}{l}20.0 \\
73.3\end{array}$ & $\begin{array}{l}15 \\
15\end{array}$ & $\begin{array}{l}50.0 \\
50.0\end{array}$ & $0.001 * * *$ \\
\hline Hypotension & $\begin{array}{l}\text { Yes } \\
\text { No }\end{array}$ & $\begin{array}{c}4 \\
26\end{array}$ & $\begin{array}{l}13.3 \\
86.7\end{array}$ & $\begin{array}{c}7 \\
23\end{array}$ & $\begin{array}{l}23.3 \\
76.7\end{array}$ & 0.35 \\
\hline $\begin{array}{l}\text { Progressive respiratory } \\
\text { failure (ARDs) }\end{array}$ & $\begin{array}{l}\text { Yes } \\
\text { No }\end{array}$ & $\begin{array}{c}4 \\
26\end{array}$ & $\begin{array}{l}13.3 \\
86.7\end{array}$ & $\begin{array}{l}15 \\
15\end{array}$ & $\begin{array}{l}50.0 \\
50.0\end{array}$ & $0.001 * * *$ \\
\hline
\end{tabular}

Independent samples t-test $P>0.05$ non significant $\quad * P<0.05$ significant $\quad * * P<0.01$ moderate significant $* * * P<0.001$ highly significant

Table (6):- Comparison between the two studied groups in relation to blood picture lab mean values by the end of the study $(n=60)$.

\begin{tabular}{|l|c|c|c|}
\hline \multicolumn{1}{|c|}{ CBC } & G1"studygroup "n=30 & G2"control group " n=30 & P value \\
\hline 1- WBC & $7.11 \pm 0.91$ & $13.26 \pm 1.41$ & $0.001^{* * *}$ \\
\hline 2- Red blood cells & $3.41 \pm 0.85$ & $3.27 \pm 0.67$ & 0.481 \\
\hline 3- Hemoglobin & $10.28 \pm 1.43$ & $9.32 \pm 0.99$ & $0.01 *$ \\
\hline 4- Hematocrit & $33.72 \pm 3.66$ & $32.95 \pm 5.36$ & 0.423 \\
\hline 5- Platelets & $218.6 \pm 46.7$ & $176.7 \pm 55.5$ & $0.001^{* * *}$ \\
\hline
\end{tabular}

Chi-square test $P>0.05$ non significant $\quad * P<0.05$ significant $* * P<0.01$ moderate significant $* * * P<0.001$ highly significant $\quad \boldsymbol{C B C}$ : complete blood picture $\quad W B C$ : White blood cells

Figure (3) : Comparison between the two studied groups in relation to the ratio of partial pressure of arterial oxygen to fraction of inspired oxygen $\mathrm{Pao}_{2} / \mathrm{fio}_{2}$ on discharge $(\mathrm{n}=60)$.

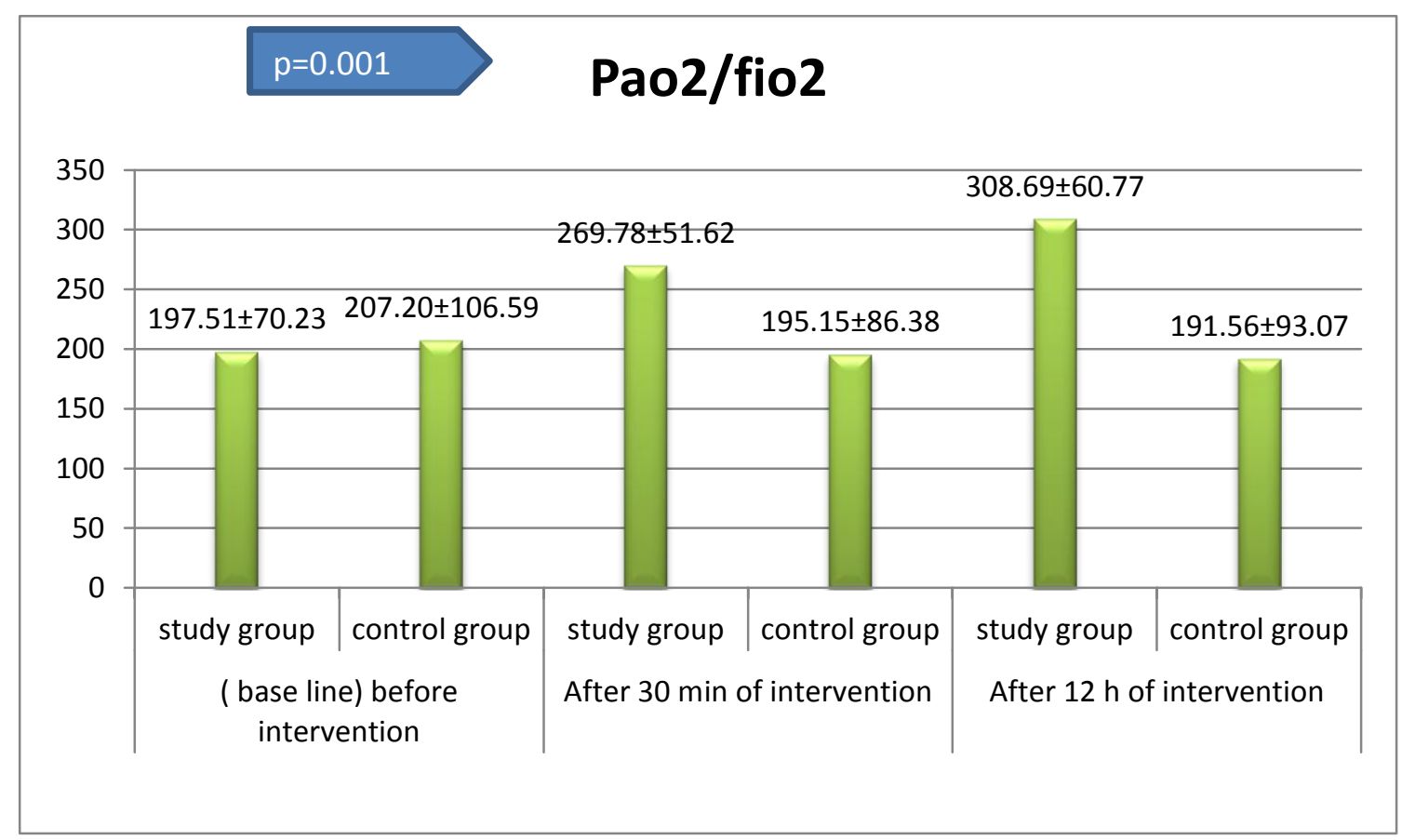


Table (1) : Shows that the highest percentage in both group in age ranged from $(31<40$ years),were male, reported no past history, diagnosed as root traffic accident, had bilateral lung lesion and had mild degree of lung injury .No significant statistical difference was put in to evidence between the two groups in relation to socio demographic \& clinical data .

Table (2): Illustrates that control group showed the tendency to have higher mean values of (HR, SBP \&DBP ,MAP,T) as compared to the study group subjects during both the after 30 minute\& after 12 hours assessment . A significant statistical difference ( $p=0.05$ to 0.01 ) founded between the two groups in relation to mean values of (HR, SBP\& DBP, MAP, T) however no significant statistical difference was founded between both groups in relation to base line assessment data.CVP readings were nearly normal between the two groups. Thus hypothesis (1) can be supported.

Table (3) : Shows that patients in the control group had higher duration connected to mechanical ventilators with Mean \pm SD of $(20.0 \pm 6.1)$ days, longer ICU stay $(25.5 \pm 8.5)$ days as compared to study group who show a statistically significant difference $(\mathrm{p}=0.05$ to 0.01$)$ duration connected to mechanical ventilators with Mean \pm SD of (14.0 \pm 5.9$)$ days, longer ICU stay(15.8 \pm 5.5$)$ day . Thus hypothesis ( 2 ) can be supported.

Table (4): Shows that the majority of study group subject $(73.3 \%)$ had complete resolution on discharge in study group compared to $(33.3 \%)$ in the control group respectively, a statistical significant difference between the both groups ( $p=0.05$ to 0.01 ) . Thus hypothesis ( 2) can be supported.

Figure (4) : Illustrates that a significant statistical difference ( $\mathrm{p}=0.05$ to 0.01 ) founded between the two groups in relation to mean values of $\left(\mathrm{PaO}_{2} / \mathrm{fio}_{2}\right.$ ratio $)$ on discharge as compared to control group subject. However no significant statistical difference was founded between both groups in relation to base line assessment data. Thus hypothesis (2) can be supported.

Table (5) : In relations to occurrence of complications (fever, hypotension, Progressive respiratory failure (ARDs) highest percentage was in control group subject (50\%) had an elevation of body temperature $(23.3 \%)$ had hypotension as compared to the study group who showed a statistically significant difference $(p=0.05$ to 0.01).Regarding to the frequency of mortality approximately similar in both groups and the difference between the two groups were not statistically significant .Thus hypothesis $(1,2)$ can be supported.
Table (6): Represents that study group showed highly significantly decreases $(p=0.05-0.01)$ regard to the mean values of WBC\& increase level of platelets \&hemoglobin concentration however the control group show increase mean values of WBC \& decrease level of platelets \& hemoglobin concentration .In relation to Hematocrit, red blood cells no statistical difference was found by the end of the study between 2 groups. Thus hypothesis $(1,2)$ can be supported.

\section{Discussion}

The aim of this study was to investigate the effect of chest Physiotherapy and recruitment maneuvers on hemodynamics and ICU stay of mechanically ventilated Patients with Acute lung Injury .

The present study presented that highest percentage of the two groups were males, more than two thirds of study in both group had Mild degree of lung injury, had Bilateral lung lesion on admission and the that highest percentage of both group did not report any past history most of them diagnosed as Root traffic accident\& multiple fractures There was no significant statistical differences between the both group. This in line with Kathy Stiller (2010) who founded there was no statistical significant difference in mean ages between both groups $(p=0.21)$ when investigate 35 patients performing twice daily CPT .This is supported by Joseph (2005) who emphasized that the nurse should be aware of the patient diagnosis as well as the lung lobes or segments involved, any structural deformities of the chest wall to help to identify the areas needing drainage and to assess the effectiveness of treatment Graham and Bradley (2012) mentioned that Chest physiotherapy should be directed at a specific lobe or segment and should be continued until auscultation reveals signs of improvement such as increased air entry and reduction of adventitial breath sounds.

Effect of nursing management (chest physiotherapy ) and recruitment maneuver on hemodynamic parameters

Regarding to the heart rate the mean heart rate was higher among control group comparing to study group after 30 min CPT\&RM the difference between the two groups were highly significant $(\mathrm{p}=0.001)$. while after $12 \mathrm{~h}$ of CPT\&RM the heart rate nearly normal in both groups the mean value the difference between the two groups were highly significant $(\mathrm{p}=0.05)$. This improvements of hemodynamics could be explained by the improvement in lung mechanics as well as parameters of the performing CPT \&RM that suppress abnormally elevated sympastic activity.The similarity of the present study was 
founded in various studies done to determine the effect of chest physiotherapy by Mackenzie, (2011) Luiz Carlos et al., (2011) they founded a statistically significant improvement of HR in study group ( $\mathrm{p}<$ 0.01 ) occurred immediately, after $1 / 2$ an hour and after 12 hours after performing chest physiotherapy compared to the values before CPT.

In relation to systolic \& diastolic blood pressure it was observed that the mean value of SBP \&DBP were decreased in study group compared to control group after 30 minute CPT \&RM. there were statistically significant $(\mathrm{P}=0.05)$.moreover after $12 \mathrm{~h}$ of CPT\&RM the whole study sample was normotensive.the similarity founded with Dyhr, (2009) who concluded that Recruitment manoeuvres did not significantly affect mean arterial blood pressure .Kanoore Edul et al., (2010) also founded only a modest reduction in systolic and mean arterial pressure after RM, and concluded that it is important not performing RMs in hypovolaemic or hypotensive patients. As regard to body temperature $\mathbf{C}^{\mathbf{0}}$ the findings of current study revealed that mean score in the control group was higher than those in study group after 30 minute \& 12 hours CPT \&RM. there were highly statistical significance difference between the two groups in most days of the study $(\mathrm{p}=0.001)$.

Caroline Bunker, (2012) mentioned that the critical care nurse should regular monitor measurement of vital signs includes obtaining temperature, blood pressure, pulse rate, and respiratory rate especially in traumatized patient which provide a picture of how much work the patient must do to maintain the current hemodynamic status. Also Pinsky, (2008) mentioned that it is important that the intensive care (ICU) nurse undertakes comprehensive cardiovascular assessment of the patient to determine adequacy of cardiac output and to observe for complications associated with poor cardiac output. This involves assessment of heart rate and rhythm ,blood pressure and central venous pressure peripheral perfusion, urine output and chest X-ray, as well as serum electrolytes. Philip, (2012) reported that Hemodynamic monitoring is central necessarily forms for a major aspect of intensive care nursing to ICU patients \& it is Avery important aspect especially for mechanically ventilate patient.

Regarding to capillary oxygen saturation $\left(\mathbf{S P O}_{2}\right)$ obtained by pulse oximetry .it can be observed that the mean values of $\mathrm{SPO}_{2}$ better after $30 \mathrm{~min} \& 12 \mathrm{~h}$ after CPT \&RM in the study group than the control group . the difference between two groups were statistically significant ( $p=0.001)$.HanJ.liu.y (2010) reported that The earliest indicators of hypoxemia often are change in ABG \&The most commonly used assessment of oxygenation is the partial pressure of arterial oxygen .using noninvasive monitors (pulse oximetery) is reduce the need for arterial blood gas determination ,because they allow continuous assessment of mechanically ventilated patient \&it is important to assess hemodynamics as heart rate, Oxygen saturation is the percentage of hemoglobin molecules saturated by oxygen .

In relation to the mean values of $(\mathbf{C V P})$ before CPT \&RM revealed hypovoemia among whole study sample but it was noticed that the mean values of CVP are slightly similar after 30minute of CPT \&RM. but after 12 hours after CPT \&RM it was improved in study group compared to control group. The difference between both two group were statistical significant $(p=0.01)$. As regards chest $x$ ray findings on discharge it was. $(73.3 \%$ of study group patients had complete resolution) compared to $(33.3 \%)$ in the control group respectively, $(\mathrm{p}=0.001)$. Duggan et al., (2010) emphasized that Retained airway secretions occlude the airways of Intubated and mechanically ventilated patients and The Persistent presence of sputum in the airways provide an ideal environment for colonizing organisms. Sheree comer (2008) reported that Chest X-ray is used to evaluate lung fields and it done routinely for all patients who admitted to acute care facilities In order to determine lung \&heart abnormalities , Cultures identify causative organisms when bacterial infection is present and to identify proper antimicrobial agent .

Jeonk \& Jaonis (2007) Notwithstanding these observations, evidence suggests that CPT is followed by improvements in oxygenation compliance, air entry and carbon dioxide clearance Furthermore, it has been suggested that CPT reduces the incidence of ventilator-associated pneumonia (VAP) . Lewis et al., (2008) mentioned that chest physiotherapy aims in ventilated patients are enhancement of pulmonary volumes to facilitate alveolar recruitment and clearance of bronchial secretions to reduce the risk of sudden or progressive occlusion. These benefits would be expected to accelerate weaning; however, there is no controlled data regarding the impact of CPT. Mackenzie \& colleagues (2011) applied CPT to patients with atelectasis and ARDS they concluded that that treatment resulted in resolution of radio graphically visible infiltrates and no adverse cardiopulmonary complications observed. Stiller et al., (2007) added that CPT consists of modified postural drainage, vibration and suction lead to greater radiographically visible resolution. Kerwin, (2007) founded that Radiographic resolution of lung volume loss with bronchoscopy was similar to that after the first chest physiotherapy treatment in the control group (38\% versus $37 \%$ ). 
Antonio et al., (2012) reported that the patient's vital signs must be monitored closely and respiratory function must assessed for signs of improvement. Observations should include breath sounds and equality of chest movements, respiration rate, pattern, depth and effort associated with breathing if any deterioration or distress is detected, the medical team must be notified at once and chest X-ray should be ordered. The current study revealed that Control group patients had a longer period of ventilator dependency\& in staying in ICU than the study group patients and difference was statistically significant $(\mathrm{p}=0.001)$.Although the patients had similar diagnoses and physical features. The results show that physiotherapy has a great impact on ventilator dependency and length of stay in the ICU. Antonio et al., (2012) concluded that Chest physiotherapy effectiveness is reducing mechanical ventilation support need, number of hospitalization days, incidence pulmonary infection rate and mortality in intensive care patients.

The similarity was founded with Renu et al., (2013) who founded that There were significant improvements in terms of rate of recovery in study group compared to the control group $(\mathrm{P}=0.000)$. Complication rates were higher in the control group as compared to the study group. Duration of hospitalization was longer in the control group compared to the study group in study to designed to evaluate the effect of multimodality chest physiotherapy on the rate of recovery and prevention of complications in adult ventilated patients. The similarity also founded with Mehtap et al., (2009) in a study to assess the effect of physiotherapy on ventilator dependency and lengths of intensive care unit (ICU) stay he found Control group patients had a longer period of ventilator dependency than the study group patients and difference was statistically significant $(\mathrm{p}=0.001)$ and concluded that positioning, manual hyperinflation, manual techniques, chest physiotherapy, bed exercises and mobilization have a significant effect on the length of stay in the ICU.

Margaret (2007) summarized that Positioning the patient in a side lying position improve oxygenation for patients with unilateral lung disease .Position change is dramatically improve gas exchange, shorten the patient's stay in the intensive care unit and improve the outlook for recovery, assist in matching ventilation and perfusion throughout the lung given that there is preferential blood flow to gravity dependent areas of the lung Positioning .Castro et al., (2013) founded that patients admitted in group $\mathbf{A}$ ( whom received chest physiotherapy for 24 hours) presented a lower length of stay in mechanical ventilation $(p<0.0001)$, ICU stay $(p=$ $0.0003)$, respiratory infections $(\mathrm{p}=0.0043)$ than patients admitted group B ( whom receive routine hospital with only $6 \mathrm{~h} /$ day). in study to determine effectiveness of Chest physiotherapy to reduce hospitalization and mechanical ventilation length of stay, pulmonary infection rate and mortality in ICU patients.

\section{Conclusion}

Combining Chest physiotherapy and Recruitment maneuvers are of great values for improvement of respiratory efficiency and promote Hemodynamic parameters.

\section{Recommendations}

In the light of the study findings the following recommendations are suggested

1-Further study for nursing staff caring of patient with acute lung injury knowledge and practices about chest physiotherapy .

2-Reapply this research on a larger probability sample for generalization.

3 - Chest physiotherapy combined with Recruitment maneuver seem to improve Hemodynamics and ICU stay of Mechanically Ventilated Patients with Acute Lung Injury and may benefit these patients

\section{References}

1. Boriosi, J., Sapru, A., Hanson, J., Asselin et al., (2011): Efficacy and safety of lung recruitment in pediatric patients with acute lung injury. Pediatric Critical Care Medicine, 12(4), 431.

2. Phua J., Badia J., Adhikari N., (2009): Has mortality from acute respiratory distress syndrome decreased over time? Am J Respir Crit Care Med, 179:220 Phys Therap 76:609625

3. Bernard G., Artigas A., Brigham K., ,(2011): The American-European Consensus Conference on ALI. Definitions, mechanisms, relevant outcomes, and clinical trial coordination. Am J Respir Crit Care Med; 149(3 Pt 1):818-824.

4. Spieth P., Carvalho A., Güldner A., Pelosi P., et al., ( 2009): Effects of different levels of pressure support variability in experimental lung injury. Anesthesiology, 110:14-215.

5. Potter\& Perry., (2011): Basic Nursing chapter 25 respiratory abnormalities (acute lung injury ) 6th edn..Mosby, Missouri, p.p 265-278.

6. Morton G., fontaine K., hudak M., (2009): Critical care nursing a holistics approch , chapter25 respiratory system,9th edition, lippincott williams \&wilikins P 536-561 
7. Smeltzer, S., \& Bare, B., (2012): Brunner\& suddarth's text book of medical surgical nursing, chapter (25) respiratory system, 11th ed .phlidelphia, lippincott Williams \&Willkins, p.p 626-640.

8. Smeltzer, S., \&Bare, B., (2010): Brunner\& suddarth's text book of medical surgical nursing, chapter (5) Gas exchange and respiratory function, ${ }^{10 t h}$ ed .phlidelphia , lippincott Williams \&Willkins, p.p 206-264.

9. Alspach G., (2006):- Core curriculum for critical care nursing, $6^{\text {th }}$ edition, chapter (2) pulmonary system, p.p106-108.

10. Green, S., Cheerio, Laddie! (2011):- Bidding Farewell to the Glasgow Coma Scale. Annals of emergency medicine, Vol 58 no(5)p.p: 427-430.

11. Maskara S., and Sen N., (2000): Correlation between lung injury score and serum albumin levels in patietns at risk for developing acute lung injury. Nutrition.Vol 16 no(1) p.p: 91-94.

12. Joseph, C., porta, C., Cacui, G., Casiraghi, et al., ( 2005) :- slow breathing improves arterial baroreflex sencitivity and decrease essential hypertension 46(4):714-8.

13. Kathy Stiller, Sue Jenkins, Ruth Grant, Tim Geake, (2010): Physiotherapy Theory and Practice for Acute lobar atelectasis: A comparison of two physiotherapy regimens , Vol. 12, No. 4 : Pp. 197-209

14. Graham W., Bradley D., (2012): Efficacy of chest physiotherapy and intermittent Positive pressure breathing in the resolution of pneumonia. N., Engl J Med 29: Pp.624-627,

15. Santos R., Donadio M., Blattner C., Squizani E., (2014):- Immediate Effects of Chest Physiotherapy on Hemodynamic, Metabolic, and Oxidative Stress Parameters in Subjects With Septic Shock. Respir Care. Jul 8. pii: respcare.02859.

16. Mackenzie C., Shin B., Hadi F., Imle P., (2011) : Changes in total lung-thorax compliance following chest physiotherapy. Anaesthesia Analgesia; 59: Pp. 207-210.

17. Luiz Carlos, Vitor E., Adriana G., et al., (2011): Chest associated to motor physiotherapy improves cardiovascular variables in newborns with respiratory distress syndrome_International Archives of Medicine, Pp. 4:37

18. Dyhr T., Bonde J., Larsson A., (2009): Lung recruitment maneuvers are effective in regaining lung volume and oxygenation after open end tracheal suctioning in acute respiratory distress syndrome. Critical Care 7: Pp. 55-62

19. Kanoore Edul V., Maskin L., Dubin A(2010): Effects of recruitment manoeuvres on haemodynamics, oxygen exchange and oxygen delivery in patients with acute lung injury and acute respiratory distress syndrome. Crit Care Resusc; 12: Pp.143-148

20. Caroline Rosdal, Mary T., Kowalski, ( 2012): text book of basic nursing chapter 86 (respiratory disorder ) $10^{\text {th }}$ edition phlidelphia , lippincott Williams \&Willkins,p.p 1409-1429

21. Pinsky M., (2008): Cardiovascular issues in respiratory care. Chest physiotherapy to prevent pulmonary complications after surgery; Pp. 52:39-43.

22. Philip Woodrow (2012) : intensive care nursing Afram work for practice, ,chapter (7) acute respiratory distress syndrome $3^{\text {rd }}$ edition by Elsevier ,London \& new York p.p 270-275

23. HanJ.liu.y (2010): effect of ventilator circuit changes on ventilator associated pneumonia ;a systemic review and meta analysis rep.care; $\mathrm{Pp}$. $55 ; 467-474$

24. Duggan M., Kavanag Fahy J., Dickey B., (2010) : Pulmonary atelectasis: a pathogenic perioperative entity. $\mathrm{N}$ Engl J Med, Pp. 363:2233-2247

25. Sheree comer, R., ., (2008):- Delmars critical care nursing care plans, chapter 21 mechanical ventilation $2^{\text {nd }}$ edition, USA. p.p90-115

26. Jeonk, Jaonis, suhGy., (2007 ) :- two methods of setting positive end expiratory pressure in acute lung injury an experimental computed tomography volumetric study, Pp. 22,476-483

27. Lewis P., Nichols E., Mackey G., Fadol A., et al., (2008): The effect of turning and backrub on mixed venous oxygen saturation in critically ill patients. Am J Crit Care 6: Pp.132-140

28. Stiller K., Geake T., Taylor J., Grant R., Hall B(2007):- Acute lobar atelectasis. A comparison of two chest physiotherapy regimens. Chest.;98: Pp. 1336-1340.

29. Kerwin A., Croce M., Timmons S., Fabian T., (2007): Effects of fiberoptic bronchoscopy on intracranial pressure in patients with brain injury: a prospective clinical study. J Trauma.;48: Pp. 878-882.

30. Antoine Roch, Christophe Guervilly and Laurent Papazian, (2012): Fluid management in acute lung injury and Acute respiratory distress syndrom and its effect on the respiratory system. Aust J Annals of Intensive Care, Pp. $1: 16$

31. Renu B., Gajanans. Gaudel, (2013):- Effect of multimodality chest physiotherapy on the rate of recovery and prevention of complications in patients with mechanical ventilation : Aprospective study in medical and surgical intensive care units Indian Journal of Medical Sciences, Vol. 65, No. 5, May Pp. 543:547. 
32. Mehtap M., \& Didem, K., (2009): The effect of physiotherapy on ventilatory dependency and the length of stay in an intensive care unit International Journal of Rehabilitation Research, 32: Pp. $85-88$

33. Margert S., Lellouche F., Pigeot J., et al., (2007):- Prevention of endotracheal suctioninginduced alveolar derecruitment in acute lung injury. American Journal of Respiratory and Critical Care Medicine 167: Pp. 1215-1224.

34. Castro A., Calil S., Freitas S., et al., (2013): Chest physiotherapy effectiveness to reduce hospitalization and mechanical ventilation length of stay, pulmonary infection rate and mortality in ICU patients Respir Med. Jan;107(1): Pp. 68-74. 